\title{
The aging of tungsten filaments and its effect on wire surface kinetics in hot-wire chemical vapor deposition
}

\author{
Jason K. Holt, ${ }^{\text {a) }}$ Maribeth Swiatek, David G. Goodwin, and Harry A. Atwater \\ Thomas J. Watson Laboratories of Applied Physics, California Institute of Technology, Pasadena, \\ California 91125
}

(Received 6 May 2002; accepted for publication 9 July 2002)

\begin{abstract}
Wire-desorbed radicals present during hot-wire chemical vapor deposition growth have been measured by quadrupole mass spectrometry. New wires produce $\mathrm{Si}$ as the predominant radical for temperatures above $1500 \mathrm{~K}$, with a minor contribution from $\mathrm{SiH}_{3}$, consistent with previous measurements; the activation energy for the $\mathrm{SiH}_{3}$ signal suggests its formation is catalyzed. Aged wires also produce $\mathrm{Si}$ as the predominant radical (above $2100 \mathrm{~K}$ ), but show profoundly different radical desorption kinetics. In particular, the Si signal exhibits a high temperature activation energy consistent with evaporation from liquid silicon. The relative abundance of the other $\mathrm{SiH}_{x}$ species suggests that heterogeneous pyrolysis of $\mathrm{SiH}_{4}$ on the wire may be occurring to some extent. Chemical analysis of aged wires by Auger electron spectroscopy suggests that the aging process is related to the formation of a silicide at the surface, with silicon surface concentrations as high as 15 at. \%. A limited amount (2 at. \%) of silicon is observed in the interior as well, suggesting that diffusion into the wire occurs. Calculation of the relative rates for the various wire kinetic processes, coupled with experimental observations, reveals that silicon diffusion through the silicide is the slowest process, followed by $\mathrm{Si}$ evaporation, with $\mathrm{SiH}_{4}$ decomposition being the fastest. (C) 2002 American Institute of Physics. [DOI: 10.1063/1.1504172]
\end{abstract}

\section{INTRODUCTION}

A knowledge of the primary radicals produced on the wire in a hot-wire chemical vapor deposition (HWCVD) reactor is critical to optimization of film microstructure and quality, as well as for modeling gas-phase chemistry. In the low pressure, collisionless regime, these wire-desorbed radicals may act as the primary film deposition precursors, while at higher pressure, they may react with other species in the gas phase to produce the precursors. In particular, the study by Molenbroek et al. ${ }^{1}$ suggested a direct correlation between amorphous film quality and the degree of reaction of wiregenerated $\mathrm{Si}$ in the gas phase.

Recently, it has been demonstrated that wire age has an effect on the resulting electronic properties of the grown film, ${ }^{2}$ thought to be related to differences in radical chemistries associated with aged versus new wires. No studies have examined, however, what these differences in radical chemistry might be, if they exist.

There have been a number of recent reports ${ }^{3-6}$ of the distribution of wire-desorbed radicals, following the early report by Doyle et al. ${ }^{7}$ Experiments conducted using similar detection schemes, such as vacuum ultraviolet photoionization mass spectrometry, have shown quite different results in some cases. ${ }^{4,5}$ Whether these differences are due to the different histories of the wire used or differences in the reactor condition (e.g., amorphous silicon-coated walls) is unclear.

One point that most of these studies agree on is that $\mathrm{Si}$ is the dominant radical observed at high wire temperatures (above $1800 \mathrm{~K}$ ). However, the distributions of the minor species found at lower temperatures are in discrepancy among

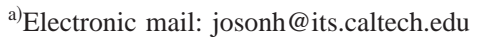

the various studies. In the report of Doyle et al., ${ }^{7} \mathrm{SiH}_{3}$ was the next most abundant radical to Si. Duan et al. ${ }^{5}$ report disilicon species $\left(\mathrm{Si}_{2} \mathrm{H}_{x}\right)$ as the next most abundant, followed by $\mathrm{SiH}_{3}$; the presence of $\mathrm{Si}_{2} \mathrm{H}_{\mathrm{x}}$ was thought to be related to wall reactions, however, and not a result of wire processes. Tange et al. ${ }^{4}$ report $\mathrm{SiH}_{2}$ as the next most abundant radical, followed by $\mathrm{SiH}_{3}$. In contrast to the other studies, the $\mathrm{SiH}_{2}$ and $\mathrm{SiH}_{3}$ radicals show a precipitous drop above $1700 \mathrm{~K}$. These discrepancies have motivated a detailed study of radical desorption kinetics under conditions where the wire history (as well as that of the reactor) is well known. Also, a detailed chemical and surface analysis of aged wires has been made to better understand the aging mechanism.

\section{EXPERIMENT}

Measurements were performed in an ultrahigh vacuum chamber with a base pressure of order $10^{-9}$ Torr. Background gases consist mostly of residual $\mathrm{H}_{2}$ and He. Operating pressures were approximately $5 \times 10^{-6}$ Torr of a dilute (1\%) mixture of $\mathrm{SiH}_{4}$ in $\mathrm{He}$ (i.e., $\mathrm{SiH}_{4}$ partial pressures of $5 \times 10^{-8}$ Torr), at flow rates of less than $1 \mathrm{sccm}$. These low pressures were chosen in order to eliminate the effects of gas-phase reactions and focus exclusively on wire processes. A straight tungsten wire of $0.5 \mathrm{~mm}$ diam and $12 \mathrm{~cm}$ length was used. Although other studies, such as that of Tange et al., ${ }^{4}$ have examined alternate wire materials (tantalum and molybdenum), tungsten was chosen due to its low vapor pressure across the temperature range of interest. Tungsten is also the most widely used wire material in HWCVD.

The wire temperature was determined by using a single wavelength, disappearing filament optical pyrometer (Leeds and Northrup, Model 8622-C), with corrections made for effective emissivity. The emissivity of elemental tungsten 
was taken as $0.44,{ }^{8}$ along with a quartz transmission factor of 0.93 , to give an effective value of 0.41 . For the temperature dependent radical measurements of the present study, the largest source of error comes from the wire temperature determination (limited by the visual acuity of the user) and is estimated to be approximately $\pm 50 \mathrm{~K}$ over the entire temperature range investigated.

Radical measurements were made with the use of a quadrupole mass spectrometer (Hiden Analytical Ltd., HAL RC 201), with the capability of tunable electron energy to enable radical detection. The radical detection technique used here relies on the lower electron energy for direct radical ionization $\left(e^{-}+\mathrm{A} \rightarrow \mathrm{A}^{+}+2 e^{-}\right)$versus ion production by dissociation of a parent molecule $\left(e^{-}+\mathrm{AB} \rightarrow \mathrm{A}^{+}+\mathrm{B}\right.$ $\left.+2 e^{-}\right) .{ }^{9}$ Measurements are made at a fixed electron energy over a range of masses. ${ }^{10}$ The electron energy chosen for these measurements was $10.5 \mathrm{eV}$, as it was found to result in preferential ionization of radical species, limiting the extent of dissociative ionization of $\mathrm{SiH}_{4}$ to produce $\mathrm{SiH}_{x}(x$ $=0-3)$. The choice of energy is critical, as interference from $\mathrm{SiH}_{4}$ dissociation at high energies can reduce the radical detection sensitivity. In addition, a characteristic of electron impact ionization, in contrast to a process such as photoionization, is the spread in the energy distribution (estimated to be $0.5 \mathrm{eV}$ full width half-maximum for our instrument). This spread allows for dissociative ionization of $\mathrm{SiH}_{4}$ at energies that are nominally below the appearance potential of a particular radical, an effect similar to that previously noted by Hsu et al. ${ }^{9}$ We find this effect to be most important for the $\mathrm{SiH}_{3}$ radical, given that $\mathrm{SiH}$ and $\mathrm{SiH}_{2}$ are only trace in abundance, and that the gap between ionization and appearance potentials is slightly smaller for $\mathrm{SiH}_{3}(3.9 \mathrm{eV})$ than for $\mathrm{Si}$ $(4.3 \mathrm{eV}) .{ }^{11}$ As a result, the data to be presented have been corrected for trace dissociative ionization by a method to be discussed in the next section. A related effect that could potentially bias the measurement of radicals is ion production from vibrationally excited $\mathrm{SiH}_{4}$, at energies below the nominal appearance potential of the particular ion. The relatively small signals we observed from $\mathrm{SiH}_{4}^{+}$, however, which would be expected to be large in the case of vibrational excitation, ${ }^{12}$ are evidence that this effect is not important.

Since the chamber used in this study is also used during high-pressure film growth, a thin layer of amorphous silicon is often observed on the walls. In order to eliminate the contribution of etching of this silicon from the walls to the measured radical signals, the chamber was cleaned by introducing $\mathrm{H}_{2}$ at total pressures in the range of 100 mTorr (10-20 $\mathrm{sccm}$ ), at a wire temperature of approximately $2200 \mathrm{~K}$. Under these conditions, a large flux of atomic $\mathrm{H}$ can be generated, and this species can effectively clean the chamber by etching amorphous silicon at rates up to $200 \mathrm{~nm} / \mathrm{min}$, as reported by Uchida et al. ${ }^{13}$

The raw data obtained by this technique consists of a scan in masses (28-32 amu) at a fixed electron energy of $10.5 \mathrm{eV}$. To obtain the raw signal intensity for each species, the spectrum was integrated across a 1 amu interval (e.g., 27.5 to $28.5 \mathrm{~m} / \mathrm{z}$ for $\mathrm{Si}$ ). A background scan was made with no $\mathrm{SiH}_{4}$ present and the wire on, and this was subtracted from the raw data. Next, a scan was made with the gas

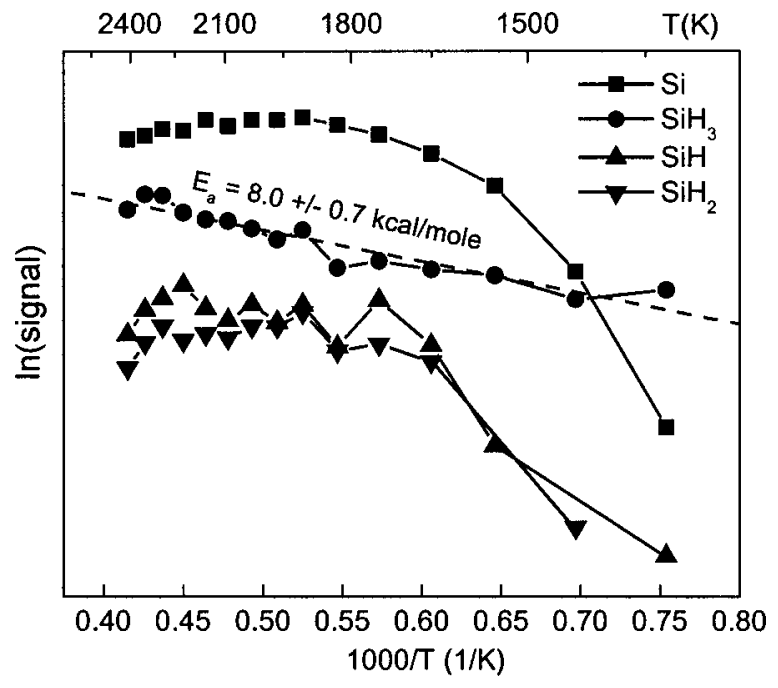

FIG. 1. Low-pressure $\left(5 \times 10^{-6}\right.$ Torr $)$ radical species measurements obtained using a new W wire. Activation energy accurate to within $\pm 10 \%$, due to wire temperature uncertainties $( \pm 50 \mathrm{~K})$; error bars are not shown.

present, but the wire off in order to assess the extent of dissociative ionization of $\mathrm{SiH}_{4}$ at $10.5 \mathrm{eV}$, due to the finite electron energy distribution. In order to subtract this additional background contribution, a gas temperature correction was necessary as these data were acquired with the wire off. Comparing the signal intensity of Ar, with and without the wire on (and applying a mass correction factor since intensity $\sim$ mass $^{-1 / 2}$ ), enabled the wire off data to be normalized and then subtracted from the raw data. Also, since the raw data at masses 29 and 30 includes not only the contribution from the $\mathrm{SiH}$ and $\mathrm{SiH}_{2}$ radicals, but contributions from $\mathrm{Si}$ isotopes $\left({ }^{29} \mathrm{Si}: 4.7 \%\right.$ abundance; ${ }^{30} \mathrm{Si}: 3.1 \%$ abundance $)$, a correction was necessary to extract the radical contribution. Given the differing efficiencies with which the various radicals can be ionized (electron ionization cross sections), normalization of the background-corrected data is necessary to determine their relative abundance. The cross section for $\mathrm{Si}$ comes from the measurements by Freund et al. ${ }^{14}$ For the other $\mathrm{SiH}_{x}$, cross section measurements by Tarnovsky et $a l .{ }^{15}$ were used. After subtracting the background contributions to the raw data, the cross section normalization was applied. The sensitivity attainable with this technique is estimated to be better than 1 ppm, taking the ratio of the minimum distinguishable radical signal (of order $10^{-12}$ Torr) to the total pressure (of order $10^{-6}$ Torr).

\section{RESULTS}

\section{A. Radical detection: New wire}

The distribution of monosilicon radical species as a function of wire temperature $(1300-2500 \mathrm{~K})$, at a total pressure of $5 \times 10^{-6}$ Torr, is shown in Fig. 1. These results were obtained with a new wire having had no previous $\mathrm{SiH}_{4}$ exposure. In order to be able to measure results for a bare wire without silicide formation, the highest temperature measurements were made first, and then the wire temperature was decreased in steps to $1300 \mathrm{~K}$. Starting at the lowest tempera- 


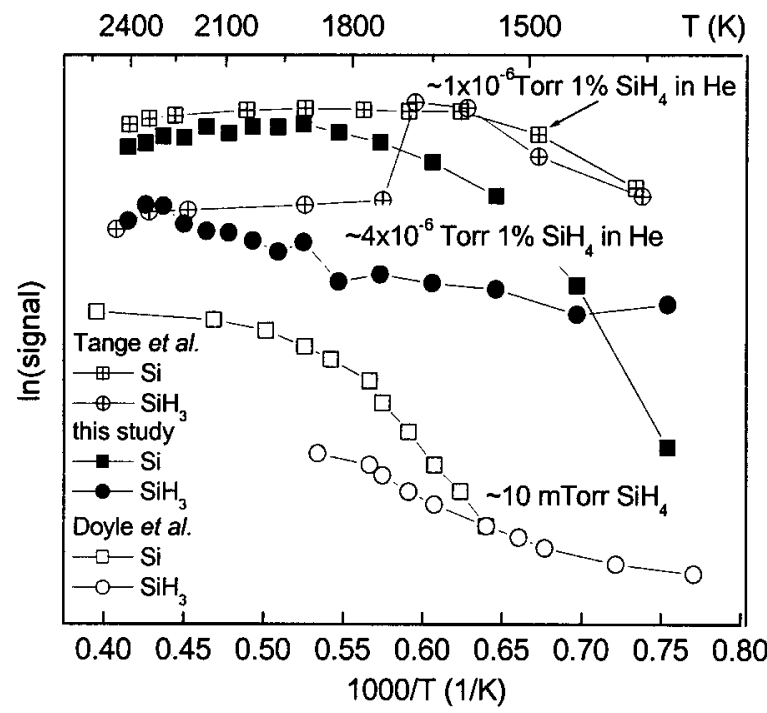

FIG. 2. Summary of experimental studies on W wire surface kinetics.

tures, at which point a silicide or Si film forms, ${ }^{7}$ revealed a hysteresis in the Si signal, likely related to the desorption of this silicide or Si film from the wire.

Figure 2 compares the results of this study to those of similar low-pressure studies (also utilizing W wires). ${ }^{4,7}$ The only species shown in Fig. 2 are $\mathrm{Si}$ and $\mathrm{SiH}_{3}$, as they were the predominant species in the present study, as well as in that of Doyle et al. ${ }^{7}$ In the study of Tange et al. ${ }^{4}$ the $\mathrm{SiH}_{2}$ signal exhibited very similar characteristics as $\mathrm{SiH}_{3}$ and thus is omitted for clarity. Similar to the other studies, ${ }^{4,5,7}$ we find that $\mathrm{Si}$ is the predominant radical desorbed from the wire for wire temperatures above $1500 \mathrm{~K}$. Above $1800 \mathrm{~K}$, a saturation in the $\mathrm{Si}$ signal is noted, with a slight decrease above 2300 $\mathrm{K}$, an effect also observed in previous studies. ${ }^{4,5,7}$ This phenomenon has been attributed to competition between desorption and decomposition; ${ }^{16}$ it should be pointed out that diffusion of Si through the wire may also be important at these high temperatures. The observation of primarily Si desorption at high temperatures indicates that surface decomposition of $\mathrm{SiH}_{4}$ is faster than evaporation of $\mathrm{SiH}_{x}$ at these temperatures.

The second most abundant radical evident from Fig. 1 is $\mathrm{SiH}_{3}$, in agreement with the report by Doyle et al. ${ }^{7}$ Over the entire temperature range investigated $(1300-2500 \mathrm{~K})$, this radical signal shows a small activation energy of $8 \mathrm{kcal} / \mathrm{mol}$, regardless of the condition of the wire surface. As the formation of this species is believed to involve an $\mathrm{H}$ atom exchange at the surface, such a small, constant activation energy is reasonable. ${ }^{7}$ Also suggested by this result is that $\mathrm{SiH}_{3}$ formation is catalyzed as this activation energy is much smaller than the bond dissociation energy of $\mathrm{SiH}_{4}(90 \mathrm{kcal} /$ mol, Ref. 17). The radicals $\mathrm{SiH}$ and $\mathrm{SiH}_{2}$ were detected in small quantities $(<8 \%$ of $\mathrm{Si}$ ), only slightly larger than the isotopic contributions from ${ }^{29} \mathrm{Si}(4.7 \%)$ and ${ }^{30} \mathrm{Si}(3.1 \%)$.

\section{B. Radical detection: Aged wire}

A recent study by Mahan $e t a .^{2}$ focused on the effect of wire alloying on the electronic properties of hydrogenated

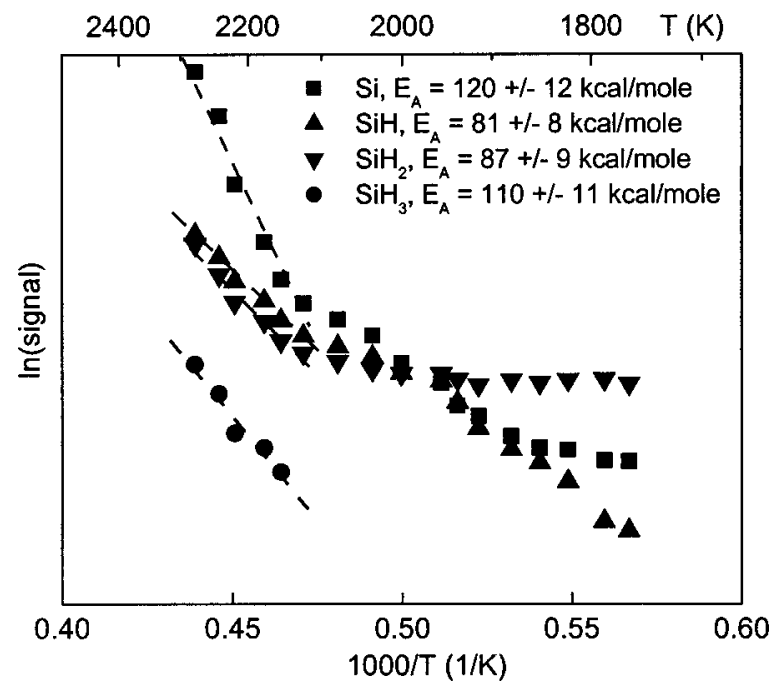

FIG. 3. $\mathrm{SiH}_{x}$ radical signals measured from an aged $\mathrm{W}$ wire at a total pressure of $5 \times 10^{-6}$ Torr. Activation energies quoted are accurate to within $\pm 10 \%$, due to uncertainties $( \pm 50 \mathrm{~K})$ in wire temperature; error bars are not shown.

amorphous silicon films. They suggested that the differences in film electronic properties observed were most likely related to differences in radical chemistries associated with a "virgin" wire versus an alloyed wire. As a means of investigating whether there are discernable differences in radical chemistry depending on the condition of the wire, we have made low-pressure radical measurements on aged wires to complement those performed on new wires. The temperature dependence of the $\mathrm{SiH}_{\mathrm{x}}$ radical signals with the use of an aged wire (one used on several previous deposition runs, with $\mathrm{SiH}_{4}$ partial pressures of order 10 mTorr and temperatures of $2000{ }^{\circ} \mathrm{C}$ ) is shown in Fig. 3. The primary differences in surface kinetics with the use of the aged wire are the observation of high temperature $(>2100 \mathrm{~K})$ activation energies for all radicals detected, as compared with the signals detected for a new wire, shown in Fig. 1. In particular, the $\mathrm{SiH}_{3}$ signal exhibits an activation energy of $106 \mathrm{kcal} / \mathrm{mol}$, substantially higher than the $8 \mathrm{kcal} / \mathrm{mol}$ observed with a new wire, and close to the $\mathrm{Si}-\mathrm{H}$ bond dissociation energy of $\mathrm{SiH}_{4}$. This suggests that the aging of the wire has led to a reduction, if not an elimination, of its catalytic activity. It is also noteworthy that the high temperature activation energy measured for $\mathrm{Si}(117 \mathrm{kcal} / \mathrm{mol})$ is close to the known heat of vaporization of $\mathrm{Si}(92 \mathrm{kcal} / \mathrm{mol})$, within experimental uncertainties. Also, in contrast to the results obtained with the new filament, $\mathrm{SiH}$ and $\mathrm{SiH}_{2}$ are both in greater abundance than $\mathrm{SiH}_{3}$. The cause for this might be the contribution of heterogeneous pyrolysis to $\mathrm{SiH}_{4}$ decomposition. At low pressures, surface-initiated $\mathrm{SiH}_{4}$ pyrolysis (on the wire) should produce $\mathrm{SiH}_{2}$ predominantly, while $\mathrm{SiH}_{3}$ can be ruled out as a primary product, based on the enthalpy of its formation reaction. ${ }^{17}$ The lower formation enthalpy for $\mathrm{SiH}$ relative to $\mathrm{SiH}_{3}$, as determined by thermodynamic calculations, ${ }^{18}$ may also explain its greater relative abundance. However, it is clear that the amount of liquid Si remaining on the wire is large enough such that its evaporation dominates over pyrolysis of $\mathrm{SiH}_{4}$ to other $\mathrm{SiH}_{x}$. 

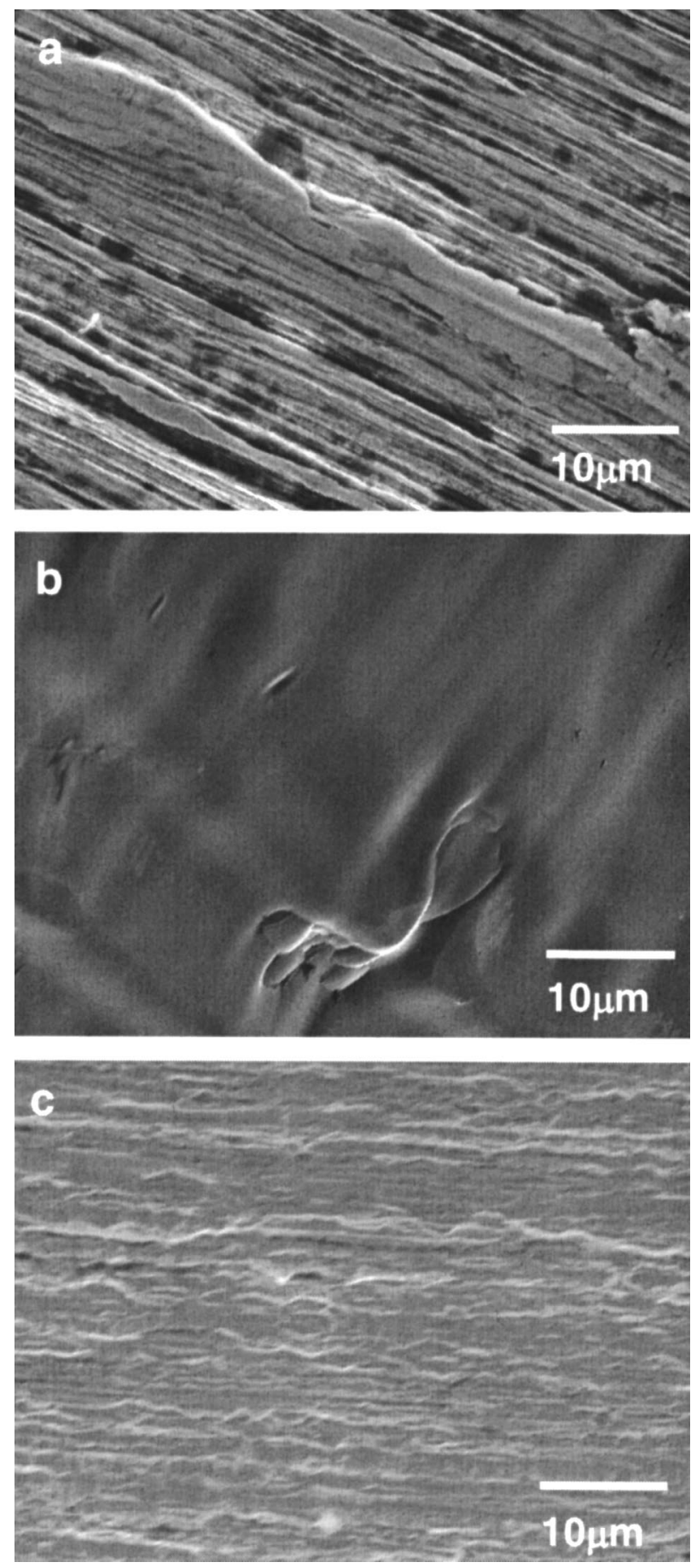

FIG. 4. Surface morphology of new (a), heat-treated (b), and aged (c) wires.

\section{Wire characterization}

\section{Scanning electron microscopy}

To complement radical measurements and gain insight into the nature of the changes occurring at the wire surface, ex situ diagnostics were performed on portions of wires, including the aged wire referred to above. Field emission scanning electron microscopy (SEM), operating at $30.0 \mathrm{kV}$ with $1.5 \mathrm{~nm}$ point resolution, was used to characterize the surface morphology of three different wires. Figure 4 depicts the SEM images of a new wire (with no previous $\mathrm{SiH}_{4}$ or high temperature exposure), a heat-treated wire (having minimal
TABLE I. Composition of used tungsten wire, as determined by Auger electron spectroscopy (AES).

\begin{tabular}{lc}
\hline \hline Location & $\mathrm{Si} /(\mathrm{Si}+\mathrm{W}) \%$ \\
\hline Surface & $11.6 \%$ \\
Surface & $15.1 \%$ \\
Interior-25 $\mu \mathrm{m}$ deep & $4.9 \%$ \\
Interior-50 $\mu \mathrm{m}$ deep & $1.9 \%$ \\
\hline \hline
\end{tabular}

$\mathrm{SiH}_{4}$ exposure at the operating temperature of $2000{ }^{\circ} \mathrm{C}$ for approximately $10 \mathrm{~h}$ ), and an aged wire (having had exposure to a partial pressure of $10 \mathrm{mTorr}^{\mathrm{SiH}_{4}}$ at $2000{ }^{\circ} \mathrm{C}$ for approximately $10 \mathrm{~h}$ ). Evident with the new wire are striations caused by the wire extrusion process, while the heat-treated wire appears to have a much smoother, glassy surface (it should be noted that the heat-treated wire also appears to have a much higher reflectivity). The properties of the heattreated wire could be a result self-diffusion of $\mathrm{W}$ along the wire surface that takes place at these high temperatures. The latter image of the aged wire reveals a much rougher, irregular surface with striation lines absent, similar to observations of Mahan $e t ~ a l . ~{ }^{2}$ for a comparably aged wire. Since the wires used during deposition go through the high temperature treatment before the introduction of $\mathrm{SiH}_{4}$, the surface morphology observed with the aged wire is attributed to deposition of $\mathrm{Si}$ (present as elemental $\mathrm{Si}$ and/or a silicide phase). Given the profound differences in surface morphology of the heat-treated and aged wire, it is not surprising that large differences in activation energies for radical desorption are observed.

\section{Auger electron spectroscopy}

To provide insight into the changes in chemical composition that occur during wire aging, Auger electron spectroscopy was used to probe discrete points at the wire surface and interior (having a spatial resolution of order $0.1 \mu \mathrm{m}$ and sampling depth of order $10 \mathrm{~nm}$ ). The measured compositions at two points along the wire surface and at two points in the interior (25 $\mu \mathrm{m}$ and $50 \mu \mathrm{m}$ depth) are given in Table I. The ratio $\mathrm{Si} /(\mathrm{Si}+\mathrm{W})$ is quoted as the other impurities detected (carbon, oxygen) were thought to be a result of ex situ contamination. As a result, the ratio $\mathrm{Si} /(\mathrm{Si}+\mathrm{W})$ should be representative of the overall fraction of $\mathrm{Si}$ in the wire during the high temperature exposure to $\mathrm{SiH}_{4}$ in the chamber. As evident from Table I, the Si concentration at the surface reaches as high as $15 \%$ and drops off precipitously to approximately $2 \%$ in the interior of the wire. It is noteworthy that the concentration in the interior is comparable to the equilibrium solid solubility of $\mathrm{Si}$ in $\mathrm{W}$ at the respective wire temperatures.

\section{DISCUSSION}

Silicon concentrations of $15 \%$ at a typical wire temperature of $2000{ }^{\circ} \mathrm{C}$ corresponds to a two-phase equilibrium between the silicide $\mathrm{W}_{5} \mathrm{Si}_{3}$ (33\% abundance) and tungsten (67\% abundance) at a silicon solubility of $4 \% .{ }^{19}$ The Auger measurements support the idea that the nature of the wire alloying or aging process involves the growth of a silicide 


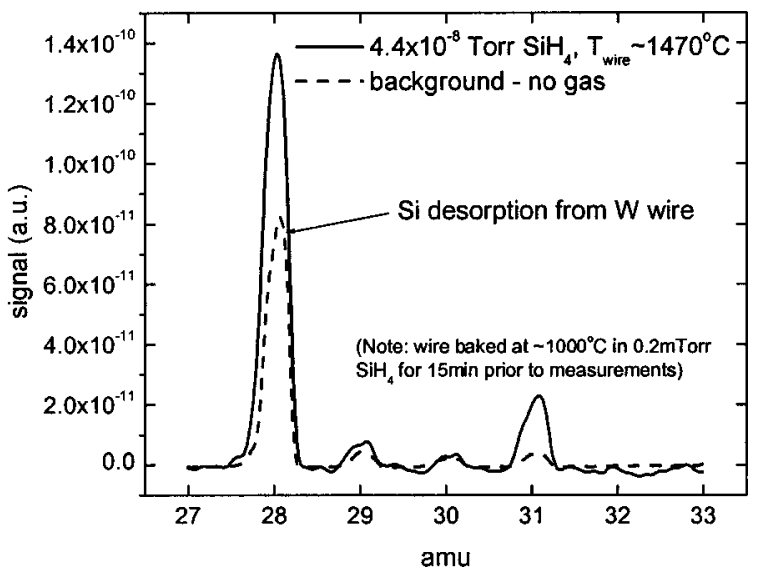

FIG. 5. Mass spectrometry evidence for Si incorporation by W wire.

layer. Given that, at a depth of $10 \%$ of the wire radius $(25$ $\mu \mathrm{m})$, silicon is present only up to its solubility limit, the silicide layer is likely to be thin. Under more severe conditions (larger $\mathrm{Si}$ concentrations at lower temperatures), the silicide constitutes a large fraction of the wire. As the silicide is more brittle than elemental tungsten, this leads to the wire breakage so commonly observed in HWCVD reactors.

To provide some insight into the kinetics of Si diffusion into $\mathrm{W}$, additional radical measurements were made. A standard aging treatment was adopted for these measurements, consisting of a 15 min bake at $\sim 1000{ }^{\circ} \mathrm{C}$ in an ambient of $\mathrm{SiH}_{4}$ at a partial pressure of 0.2 mTorr $(20$ mTorr total, balance $\mathrm{He}$ ). A mass spectrum was then acquired at a higher wire temperature $\left(1470{ }^{\circ} \mathrm{C}\right)$, at a $\mathrm{SiH}_{4}$ partial pressure of $4.4 \times 10^{-8}$ Torr, followed by a scan in the absence of $\mathrm{SiH}_{4}$. Figure 5 reveals contributions from $\mathrm{Si}$ and $\mathrm{SiH}_{3}$ (produced by $\mathrm{H}$ abstraction from $\mathrm{SiH}_{4}$ ) for the case of the $\mathrm{SiH}_{4}$ background. In the absence of $\mathrm{SiH}_{4}, \mathrm{Si}$ is the predominant radical observed, and this signal is attributed to $\mathrm{Si}$ (in excess of the thermodynamic solubility) diffusing from the interior of the wire; this signal was observed to persist for more than $1 \mathrm{~h}$, with no decrease in intensity. Comparing the relative magnitudes of the two signals, one estimates that the diffusion signal corresponds to a $\mathrm{SiH}_{4}$ partial pressure of $\sim 2$ $\times 10^{-8}$ Torr (it should be noted that this contribution is relatively small compared to the $\mathrm{SiH}_{4}$ partial pressures of $>1$ mTorr, typical of growth conditions). For an assumed average concentration of $1 \% \mathrm{Si}$ throughout the entire wire, a simple calculation shows that the corresponding pressure would be $\sim 30$ mTorr, at a typical wire temperature of 1800 ${ }^{\circ} \mathrm{C}$. This result suggests that the time scale to completely deplete the wire of its $\mathrm{Si}$ is extremely long, consistent with the mass spectrometry observations suggesting Si diffusion.

A comparison of the relative rates for the various surface kinetic processes, namely, diffusion, evaporation, and decomposition allows further insight into the nature of the wire aging process. At the highest temperatures investigated in this study $(\sim 2400 \mathrm{~K})$, the solid solubility of $\mathrm{Si}$ in $\mathrm{W}$ is a few atomic percent, dropping to less than 1 at. \% at the lowest temperature $(1273 \mathrm{~K})$. To our knowledge, there have been no studies that examined the diffusion of Si into elemental W. A study by Kharatyan et al. ${ }^{20}$ however, investigated the diffusion of Si into various silicides of tungsten and molybdenum.

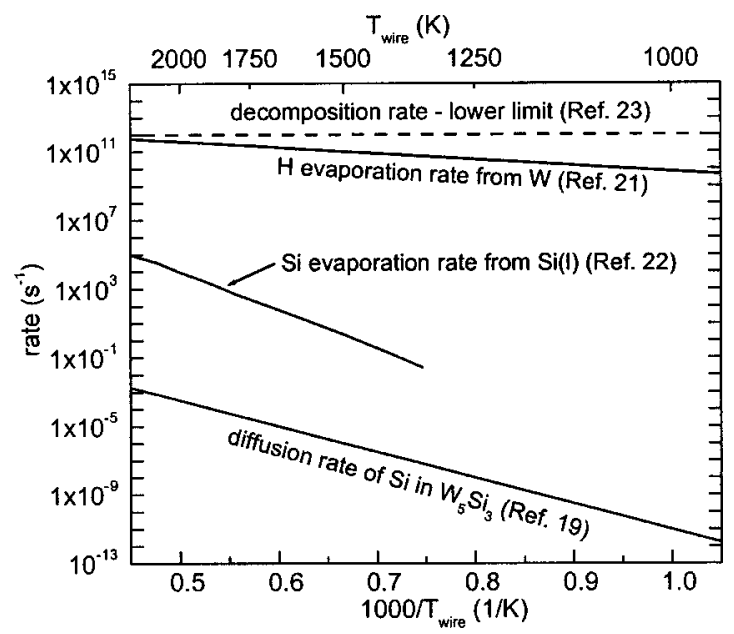

FIG. 6. Rates of interest for wire surface kinetic processes.

For the diffusion of $\mathrm{Si}$ into $\mathrm{W}_{5} \mathrm{Si}_{3}$ (the only silicide for which data were available), a diffusion coefficient of

$$
D_{\mathrm{W}_{5} \mathrm{Si}_{3}}^{\mathrm{Si}}=6.9 \exp (-69000 \pm 5000 / \mathrm{RT}), \mathrm{cm}^{2} / \mathrm{s}
$$

was obtained. ${ }^{20}$ Using this diffusion coefficient, the time scale for diffusion (using the wire radius as a lower limit for the characteristic length) as a function of wire temperature is given in Fig. 6.

Data on the evaporation rate of Si from W were unavailable, but the study by Ehrlich ${ }^{21}$ does provide an evaporation rate for $\mathrm{H}$ from $\mathrm{W}^{22}$ which is relevant to the $\mathrm{SiH}_{4}$ decomposition process; this rate is plotted in Fig. 6. The evaporation rate of $\mathrm{Si}$ from liquid $\mathrm{Si}$ could be determined from the vapor pressure data of Margrave. ${ }^{23}$ As liquid Si can form at some point during the aging process $(\mathrm{W}<33 \% / \mathrm{Si}>66 \%),{ }^{19}$ this rate has relevance to the aged wires of this study. This rate of evaporation, as a function of wire temperature, is also plotted in Fig. 6. Finally, rates of $\mathrm{SiH}_{4}$ decomposition on $\mathrm{W}$ were not directly available, but a study by Yang et al. ${ }^{24}$ suggests the time scale for $\mathrm{Si}-\mathrm{H}$ bond breaking is of order a few picoseconds (in a liquid environment), establishing a lower bound to the decomposition rate for the significantly higher temperatures in the present study; this rate is included for comparison in Fig. 6.

Examining these rates in Fig. 6, the bulk diffusion of $\mathrm{Si}$ through the silicide is clearly the slowest process, followed by $\mathrm{Si}$ evaporation, and then decomposition. These rates, coupled with experimental observations, give a picture of the relative rates of surface kinetic processes on the wire. First, the high rate of decomposition compared with evaporation and diffusion suggests that for the vast majority of wire temperatures, $\mathrm{Si}$ (as opposed to other $\mathrm{SiH}_{x}$ ) is the predominant evaporating/diffusing species; radical measurements in particular support the idea that it is the dominant evaporating species. Next, the Auger and radical measurements described earlier provide clear evidence that diffusion through the wire is occurring, and at rates faster than predicted by bulk diffusion alone. This suggests that the majority of Si that diffuses into the wire does so before a thick silicide has formed. Whether this higher effective diffusivity is due to a higher intrinsic rate of $\mathrm{Si}$ diffusion into $\mathrm{W}$ (rather than $\mathrm{W}_{5} \mathrm{Si}_{3}$ ) or 
diffusion occurring primarily through cracks that develop on the surface of the wire, is unclear. Finally, it appears that the rate of evaporation of $\mathrm{Si}$ from $\mathrm{Si}(1)$ is several orders of magnitude below that of decomposition, even at the highest wire temperatures. It was previously observed, however, that for wire temperatures in excess of $2000 \mathrm{~K}$, a saturation in the $\mathrm{Si}$ signal occurs with the use of a new wire that does not occur with an aged wire. This observation is consistent with a competition between evaporation and decomposition. This, in turn, suggests that the mechanism of Si desorption from a new wire does not consist of $\mathrm{Si}$ evaporation from $\mathrm{Si}(1)$, but a different mechanism, namely, the direct desorption of $\mathrm{Si}$ from a W surface. The rate for this process is likely to be of a similar magnitude as $\mathrm{H}$ evaporation from $\mathrm{W}$, depicted in Fig. 6.

A picture then emerges of the hot-wire CVD decomposition process. First, $\mathrm{SiH}_{4}$ is adsorbed and then rapidly decomposed to $\mathrm{Si}$ and $\mathrm{H}$ on the surface of a new wire. This surface $\mathrm{Si}$ will then either evaporate or, if the surface concentration is high enough, diffuse to the interior of the wire up to its solubility limit. Once the thermodynamic solubility has been reached, excess $\mathrm{Si}$ can contribute to the formation of the $\mathrm{W}_{5} \mathrm{Si}_{3}$ phase, or at higher concentrations, $\mathrm{WSi}_{2}$. At the highest $\mathrm{Si}$ concentrations $(>67 \%)$, liquid $\mathrm{Si}$ can form at the surface and then $\mathrm{Si}$ evaporation from $\mathrm{Si}(1)$ becomes the dominant mechanism of Si production. The observation that a new wire readily absorbs $\mathrm{Si}$, but retains it for a long period of time, can be explained as a silicide diffusion-limited process. The silicide that forms at the surface acts as a diffusion barrier to Si in the interior of the wire (as well as to further diffusion of surface $\mathrm{Si}$ into the wire), and Fig. 6 shows that the characteristic diffusion time at the wire temperature used $(\sim 1750 \mathrm{~K})$ is, at minimum, several hours.

\section{CONCLUSIONS}

With the use of a new wire, $\mathrm{Si}$ is found to be the predominant radical produced in a HWCVD system for wire temperatures in excess of $1500 \mathrm{~K}$. For temperatures below $1500 \mathrm{~K}$, the $\mathrm{SiH}_{3}$ radical becomes predominant. The small activation energy $\left(8 \mathrm{kcal} \mathrm{mol}\right.$ ) observed for $\mathrm{SiH}_{3}$ formation suggests the process is catalyzed with the use of these wires. These results are in qualitative agreement with previous studies of radical chemistry at the wire. Radical measurements performed on aged wires show high temperature activation energies for all $\mathrm{SiH}_{x}$ species, suggesting a noncatalyzed process for radical formation.

Scanning electron microscopy of aged wires revealed a surface both rougher and more irregular than seen with new or heat-treated wires; this morphology is thought to be characteristic of $\mathrm{Si}$ deposition (either as free $\mathrm{Si}$ or a silicide). Auger electron spectroscopy revealed surface Si concentrations as high as $15 \%$, suggesting a two-phase equilibrium between $\mathrm{W}_{5} \mathrm{Si}_{3}$ and $\mathrm{W}$ (at a Si solubility of $4 \%$ ). Concentrations of $\mathrm{Si}$ in the interior of the wire $(2 \%-5 \%)$ are of order the solubility limit and reveal that $\mathrm{Si}$ diffusion into the wire is significant. Radical measurements added further evidence of Si diffusion, as Si was detected in a silane-free ambient following an aging treatment.
Examining rates for various surface kinetic processes reveals that bulk diffusion of Si through a silicide is the slowest, followed by Si evaporation and then surface decomposition. The high rate of surface decomposition supports the idea that $\mathrm{Si}$ is in fact the predominant evaporating and diffusing species. In light of the low rate of diffusion through the silicide, the diffusion mechanism in the initial stages of $\mathrm{SiH}_{4}$ exposure must either consist of bulk diffusion through elemental $\mathrm{W}$ or large cracks that develop on the wire surface and propagate to the interior of the wire. Finally, experimentally observed evaporation kinetics suggest that Si desorption from a new wire comes from direct $\mathrm{Si}-\mathrm{W}$ bond breakage, as opposed to evaporation from $\mathrm{Si}(1)$.

\section{ACKNOWLEDGMENT}

This work is supported, in part, by the National Renewable Energy Laboratory and Applied Materials.

${ }^{1}$ E. Molenbroek, A. Mahan, E. Johnson, and A. Gallagher, J. Appl. Phys. 79, 7278 (1996).

${ }^{2}$ A. Mahan, A. Mason, B. Nelson, and A. Gallagher, Mater. Res. Soc. Symp. Proc. 6409, A.6.6.1 (2000).

${ }^{3}$ Y. Nozaki, K. Kongo, T. Miyazaki, M. Kitazoe, K. Horii, H. Umemoto, A. Masuda, and H. Matsumura, J. Appl. Phys. 88, 5437 (2000).

${ }^{4}$ S. Tange, K. Inoue, K. Tonokura, and M. Koshi, Thin Solid Films 395, 42 (2001).

${ }^{5}$ H. Duan, G. Zaharias, and S. Bent, Appl. Phys. Lett. 78, 1784 (2001).

${ }^{6}$ J. Holt, M. Swiatek, D. Goodwin, and H. Atwater, Mater. Res. Soc. Symp. Proc. 664, A.3.2.1 (2001).

${ }^{7}$ J. Doyle, R. Robertson, G. Lin, M. He, and A. Gallagher, J. Appl. Phys. 64, 3215 (1988)

${ }^{8}$ CRC Handbook of Chemistry and Physics, 61st ed. (Chemical Rubber, Cleveland, 1980), p. E-400.

${ }^{9}$ W. Hsu and D. Tung, Rev. Sci. Instrum. 63, 4138 (1992).

${ }^{10}$ This rapid method of acquiring data was chosen over that used in threshold ionization mass spectrometry (TIMS), where scans in electron energy are made at specific masses. The length of time needed for a TIMS experiment measuring all four species and acquiring reasonable statistics would have been at least a factor of 4 longer (approximately $12 \mathrm{~h}$ ). Over such a time period it was believed that drift, associated with a number of factors such as wire aging, could have biased the resulting data.

${ }^{11}$ R. Robertson, D. Hils, H. Chatham, and A. Gallagher, Appl. Phys. Lett. 43, 544 (1983).

${ }^{12}$ R. Robertson and A. Gallagher, J. Appl. Phys. 59, 3402 (1986).

${ }^{13}$ K. Uchida, A. Izumi, and H. Matsumura, Thin Solid Films 395, 75 (2001).

${ }^{14}$ R. Freund, R. Wetzel, R. Shul, and T. Hayes, Phys. Rev. A 41, 3575 (1990).

${ }^{15}$ V. Tarnovsky, H. Deutsch, and K. Becker, J. Chem. Phys. 105, 6315 (1996).

${ }^{16}$ H. Matsumura, A. Masuda, and A. Izumi, Mater. Res. Soc. Symp. Proc. 557, 67 (1999).

${ }^{17}$ J. H. Purnell and R. Walsh, Chem. Phys. Lett. 110, 330 (1984).

${ }^{18}$ R. Kee, F. Rupley, and J. Miller, Technical Report No. SAND89-8009 (1989).

${ }^{19}$ TAPP_-Thermochemical and Physical Properties, Version 2.1, ES Microware (1991).

${ }^{20}$ S. Kharatyan and H. Chatilyan, J. Prikl. Khim. Armenii (1-2), 22 (1999).

${ }^{21}$ G. Ehrlich, Adv. Catal. Rel. Subj. 14, 271 (1963).

${ }^{22}$ The Ehrlich study involved flash desorption measurements of $\mathrm{N}_{2}, \mathrm{CO}, \mathrm{H}_{2}$, and $\mathrm{H}$ below room temperature, up to $2200 \mathrm{~K}$. Molecules were allowed to adsorb at lowered temperatures for a period of $3 \mathrm{~min}$, and then the filament was heated at a constant rate, allowing desorption to be monitored by an ion gauge.

${ }^{23}$ J. Margrave, The Characterization of High-Temperature Vapors (Wiley, New York, 1967).

${ }^{24}$ H. Yang, M. Asplund, K. Kotz, M. Wilkens, H. Frei, and C. Harris, J. Am. Chem. Soc. 120, 10154 (1998). 